\title{
Evaluation of thermal and hydraulic of air flow through perforated concave delta winglet vortex generators in a rectangular channel with field synergy principle
}

Cite as: AIP Conference Proceedings 2187, 020013 (2019); https://doi.org/10.1063/1.5138268

Published Online: 10 December 2019

Syaiful, Pracayasa Ade Putra, Mohammad Tauviqirrahman, Nazaruddin Sinaga, and Myung-whan Bae

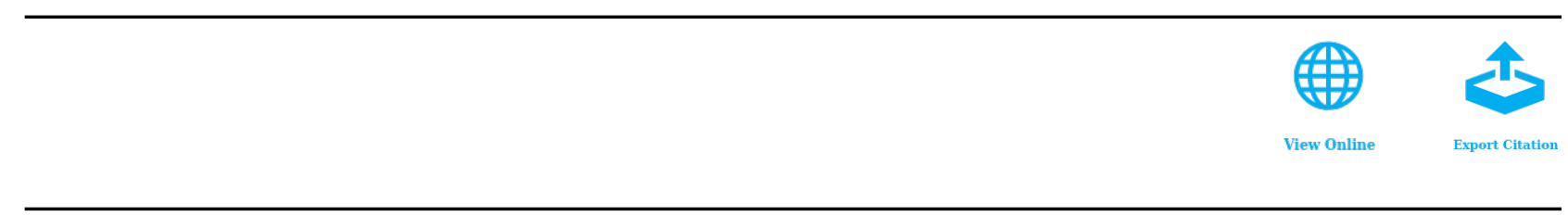

Lock-in Amplifiers up to $600 \mathrm{MHz}$

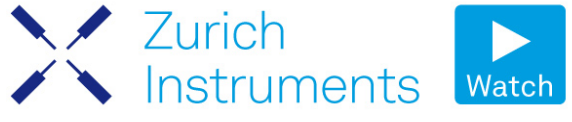

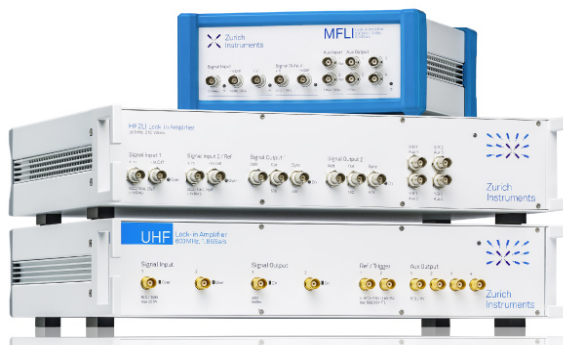




\title{
Evaluation of Thermal and Hydraulic of Air Flow through Perforated Concave Delta Winglet Vortex Generators in A Rectangular Channel with Field Synergy Principle
}

\author{
Syaiful $^{1, \mathrm{a})}$, Pracayasa Ade Putra ${ }^{1, \mathrm{~b})}$, Mohammad Tauviqirrahman ${ }^{1, \mathrm{c})}$, Nazaruddin \\ Sinaga ${ }^{1, \mathrm{~d})}$, and Myung-whan $\mathrm{Bae}^{2, \mathrm{e})}$ \\ ${ }^{1}$ Department of Mechanical Engineering, Faculty of Engineering, Diponegoro University, Jl.Prof.Soedarto, \\ Tembalang, Semarang 50275, Indonesia \\ ${ }^{2}$ Engineering Research Institute, Department of Mechanical Engineering for Production, Gyeongsang National \\ University, 501, Jinju-daero, Jinju, Gyeongsangnam-do, 660-701, South Korea \\ ${ }^{a}$ Corresponding author: syaiful.undip2011@gmail.com \\ b)adeputra14@gmail.com \\ c)mtauviq99@yahoo.com \\ d)nazarsinaga@yahoo.com \\ e)mwbae@gnu.ac.kr
}

\begin{abstract}
A compact heat exchanger can be found in air conditioning, automotive industry, chemical processing, etc. Most compact heat exchangers use gas as a heating or cooling fluid. However, gas has high thermal resistance, which affects lower heat transfer. In order to reduce thermal resistance on the gas side, the convection heat transfer coefficient is increased. One effective way to enhance the convection heat transfer coefficient is to use a vortex generator. Vortex generators are surface protrusions that are able to manipulate flow resulting in an increase in convection heat transfer coefficient by enhancing the mixture of air near the wall with the air in the main flow. Therefore, this work aims to evaluate the thermal and hydraulic characteristics of airflow through the perforated concave delta winglet vortex generator. This study was conducted on delta winglet vortex generators (DW VGs) and concave delta winglet vortex generator (CDW VGs) with the $45^{\circ}$ angle of attack with a number of hole three-holes that applied on every vortex generator with one-line fitting, two-line fitting, and three-line fitting respectively. Results of simulation revealed that heat transfer coefficient (h) for perforated CDW VGs decrease $16.07 \%$ and pressure drop decrease $7 \%$ compare to that without hole configuration at Reynolds number of 8600 . Convection heat transfer coefficient for perforated DW VGs decrease $13.76 \%$ and pressure drop decrease $5.22 \%$ compare to delta winglet without hole at Reynolds number of 8600 .
\end{abstract}

\section{INTRODUCTION}

The compact heat exchangers are designed to acquire high surface area per volume unit [1]. Compact heat exchangers are often found in applications for electricity generation, air conditioning, the chemical industry and others. One type of compact heat exchanger is fin and tube. Most fin and tubes use gas on the fin side as a heat transfer medium. However, gas has high thermal resistance, which affects the low rate of heat transfer. Therefore, the heat transfer on the airside needs to be improved [2]. Enhancement of heat transfer can be done by increasing the surface area. On fin and tube, the fin is used to increase the heat transfer surface area on the gas side. However, the addition of the fin surface area also increases the dimension of the heat exchanger with the result the efficiency of the fin is decreased. Furthermore, the enhancement of heat transfer can be done by increasing the convective heat transfer coefficient [3]. 
Vortex generator is a modification of the heat transfer surface that produces swirling motion. Swirling motion on the flow conduce the vortex. Based on the direction of the axis, the vortex can be classified into the longitudinal vortex and transverse vortex. The longitudinal vortex is a circular motion which the axis is parallel to the main flow while the transverse vortex has a perpendicular axis to the main flow. The longitudinal vortex is more effective to increase the heat transfer rate compare with transverse vortex [4]. Longitudinal vortex causes a reduction in boundary layer thickness, instability in the flow, and an increase in temperature gradient near the heat transfer surface [5].

The study of the vortex generator for convection heat transfer coefficient enhancement has been conducted by many researchers. M. Khoshcaght-Aliabadi et al. (2015) conducted the experimental study to investigate the heat transfer enhancement by using vortex generator with the different arrangement of delta winglet in a tube [6] The result of their study shows that the heat transfer rate and the pressure drop in the channel with vortex generator are higher than without vortex generator. Moreover, four delta winglet vortex generators that inserts into two side cut of plate produces the best convection heat transfer enhancement compared to the other delta winglet configuration. K. Song et al. (2016) conducted experimental on the curved delta winglet vortex generator with variation in geometry size and tube pitch on fin-tube heat exchangers [7]. The experiment was carried out on fifteen samples of circular tube-fin heat exchanger with the combination of three fin pitches, two tube pitches, and two different curved delta winglet geometries. The result shows that the curved delta winglet vortex generator increases heat transfer performance up to $18.79 \%$.

Hung-Yi Li et al. (2017) conducted the experimental study of vortex generator for increase the heat transfer rate on the pin-fin heat sink with the variation $30^{\circ}, 60^{\circ}$, and $90^{\circ}$ attack angles [8]. The result showed that the thermal resistance on the pin-fin heat sink is decreased while the Reynolds number increases. Vortex generator with the $30^{\circ}$ angle of attack is the most efficient for enhancing the heat transfer rate with the low-pressure drop. Yonggang Lei et al. (2017) conducted the numerical study of punched delta winglet vortex generator on a circular tube [9]. Their results showed that the Nusselt number is increased by increasing the angle of attack and decreasing the distance from delta winglet vortex generator. This research used field synergy angle to explain the heat transfer mechanism using delta winglet vortex generator.

The numerical study to show the comparison of heat transfer rate and the characteristic of the flow between simple trapezoidal longitudinal vortex generator and curved trapezoidal longitudinal vortex generator was carried out by A. Esmeilzadeh et al. [10]. The result of their study showed that the channel with curved trapezoidal longitudinal vortex generator observes the higher performance of heat transfer compared to that the channel with a trapezoidal longitudinal vortex generator. Uddip Kashyap et al. conducted the numerical study with the variation of surface geometry rectangular vortex generator to improve the heat transfer rate [11]. The result of their study showed that the modification on the surface of the vortex generator could increase the heat transfer rate. Some concave profiles on the leading face are very effective to enhance the Nusselt number. Syaiful et al. conducted the numerical study of thermalhydrodynamic performance fluid flow through concave delta winglet vortex generator on a rectangular channel [12]. The result of their research showed that the convection heat transfer coefficient on one, two, and three rows are increased by $65-108.45 \%, 34.4-71 \%$, and $42.2-110,7 \%$, respectively, compared to that of baseline. However, the increase of the convection heat transfer coefficient is accompanied by the increase in pressure drop.

Based on literature studies, discussions relating to the use of perforated concave vortex generators are rather rare. Therefore, the present work tries to focus on investigating the use of perforated concave delta winglet vortex generators to improve heat transfer.

\section{MODEL DESCRIPTION}

\section{Experimental Set-up}

The experimental study was carried out on a rectangular channel made of $10 \mathrm{~mm}$ thick glass and the dimension of $370 \mathrm{~cm}$ length, $8 \mathrm{~cm}$ wide, and $18 \mathrm{~cm}$ high, as shown in Figure 1. The air was sucked by a blower into the channel from the inlet side through the straightener which consists of a $5 \mathrm{~mm}$ diameter pipe arrangement and wire mesh for forming uniform velocity. The inlet air velocity was varied from $0.4 \mathrm{~m} / \mathrm{s}$ to $2.0 \mathrm{~m} / \mathrm{s}$ with interval of $0.2 \mathrm{~m} / \mathrm{s}$. The air velocity entering into the channel was regulated by using a regulator which is controlled by an inverter (Mitsubishi Electric FR-D700 with the accuracy of $\pm 0.01 \mathrm{~Hz}$ ). The air velocity was measured by hot-wire anemometer (Lutron type AM-4204 with accuracy \pm 0.05 ). A test plate with/without vortex generators was heated at a constant rate of 35 W using a heater which was adjusted by a regulator heater connected to a wattmeter (Lutron DW-6060 with the 
accuracy of \pm 0.01 ) for monitoring the heat rate of the heater. Some K type thermocouples were mounted on the surface of the plate and on the outlet to measure the wall temperature and outlet temperature. Thermocouples were processed by a data acquisition (Advantech type USB-4718 with accuracy \pm 0.01 ) that connected to the CPU. Two pitot tubes were installed at the inlet and outlet sides of the test specimen and connected to a micromanometer (Fluke type 922 with an accuracy of \pm 0.01 ) for monitoring the pressure drop value.

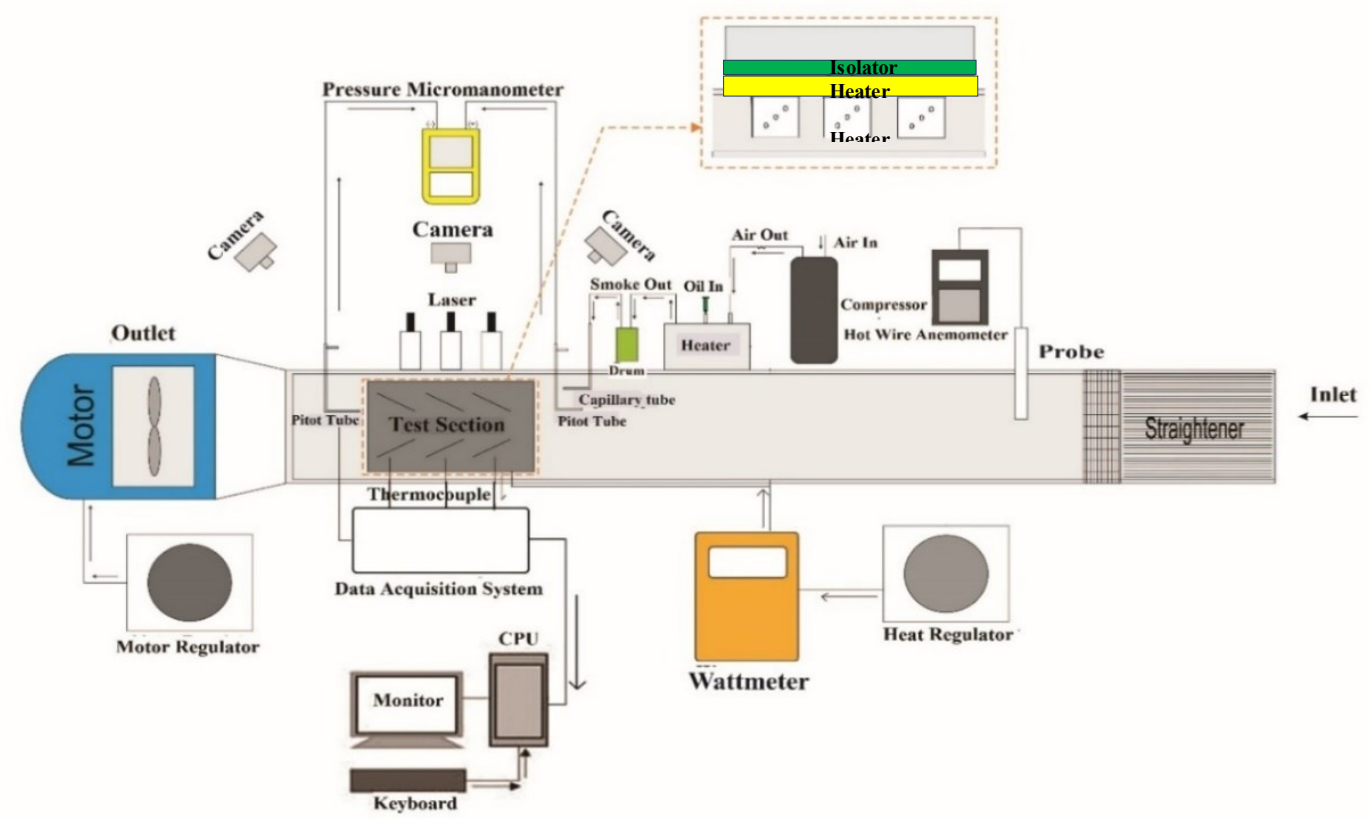

Figure 1.Experimental set-up

\section{Physical Model}

This work was carried out in a rectangular channel with a flat plate heated with/without vortex generators. In this study, the effect of using CDW vortex generators (CDW VGs) and DW vortex generators (DW VGs) on thermal and hydraulic performance is compared. Figure 2 shows the geometry of the vortex generator used in this study with the detailed geometry is demonstrated in Table 1. In this study, the vortex generator was made of aluminum plate with a thickness of $1 \mathrm{~mm}$. For the analysis, CDW and DW VGs with three holes were compared with that without holes. Figure 3 shows the top view of the DW and CDW VGs. VGs were arranged in a common flow-down orientation with an attack angle $(\alpha)$ of 45 at a pitch longitudinal distance of $125 \mathrm{~mm}$. The distance of the first row of VGs with the inlet channel is $125 \mathrm{~mm}$. The transverse distance leading to the winglet pairs of VGs is $20 \mathrm{~mm}$. The rectangular channel has dimensions of length $(\mathrm{P})$, width $(\mathrm{L})$, height $(\mathrm{H})$ channels of $500 \mathrm{~mm}, 75.5 \mathrm{~mm}, 43 \mathrm{~mm}$, respectively. 
Three Holes CDWP

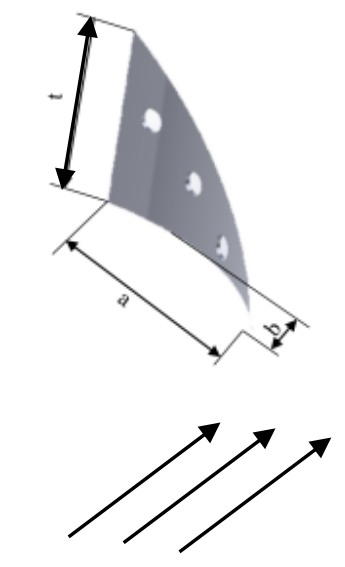

Airflow

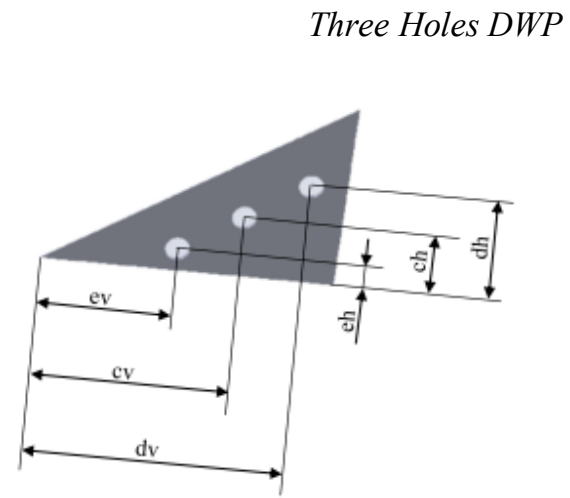

Figure 2.The detailed geometry of CDW and DW vortex generator

Table 1. Geometric parameter of vortex generator

\begin{tabular}{|c|c|c|c|c|c|c|c|c|c|c|c|}
\hline VGs & $\alpha\left(^{\circ}\right)$ & $\mathrm{a}(\mathrm{mm})$ & $\mathrm{b}(\mathrm{mm})$ & $\operatorname{cv}(\mathrm{mm})$ & $\mathrm{dv}(\mathrm{mm})$ & $\mathrm{ev}(\mathrm{mm})$ & $\operatorname{ch}(\mathrm{mm})$ & $\mathrm{dh}(\mathrm{mm})$ & $\mathrm{eh}(\mathrm{mm})$ & $\mathrm{t}(\mathrm{mm})$ & $\mathrm{R}(\mathrm{mm})$ \\
\hline 3 Holes CDW & 45 & 56 & 9 & 35 & 47 & 20 & 13.3 & 21.6 & 5 & 40 & 58 \\
\hline 3 Holes DW & 45 & 60 & - & 40 & 52.5 & 27.5 & 13.3 & 21.6 & 5 & 40 & - \\
\hline
\end{tabular}

Figure 4 shows the computational domain, along with the coordinate system used in this study. The $\mathrm{x}, \mathrm{y}$, and zaxes show the direction of the flow, which are streamwise, spanwise, and the normal wall, respectively. The dashed line in Figure 4(a) shows the computational domain. This computational domain was chosen because the channel geometry has a form of symmetry. Figure 4(b) shows the computational domain with the upstream and downstream extended regions. The upstream extended region serves to ensure that the fluid flow entering the computational domain is fully developed and downstream extended region is to ensure that the fluid flow does not experience reverse flow in the outlet region. 


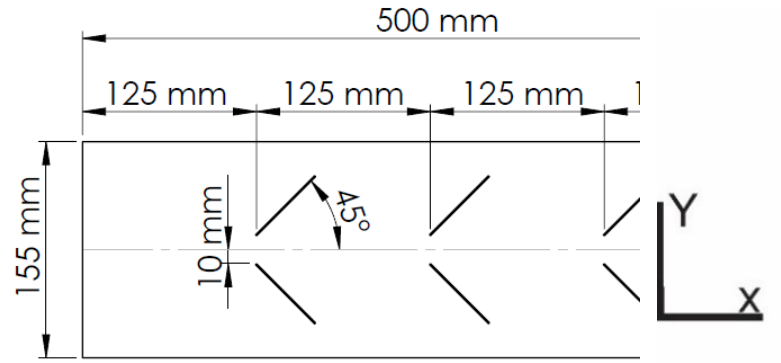

(a)

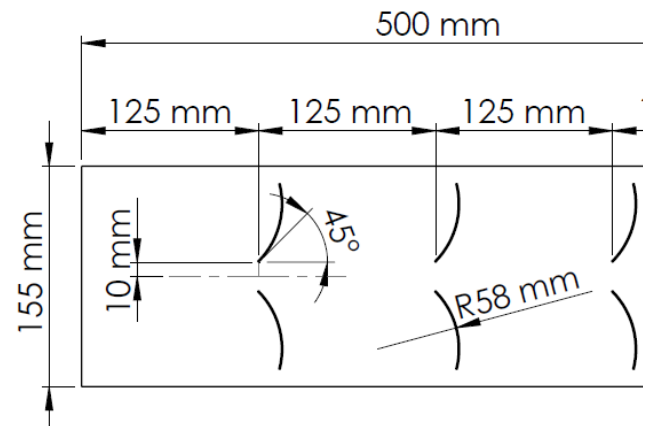

(b)

Figure 3.Top view of: (a) DW VGs and (b) CDW VGs

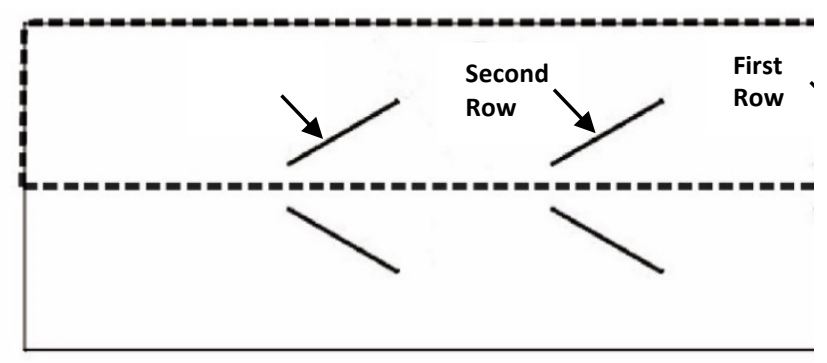

(a)

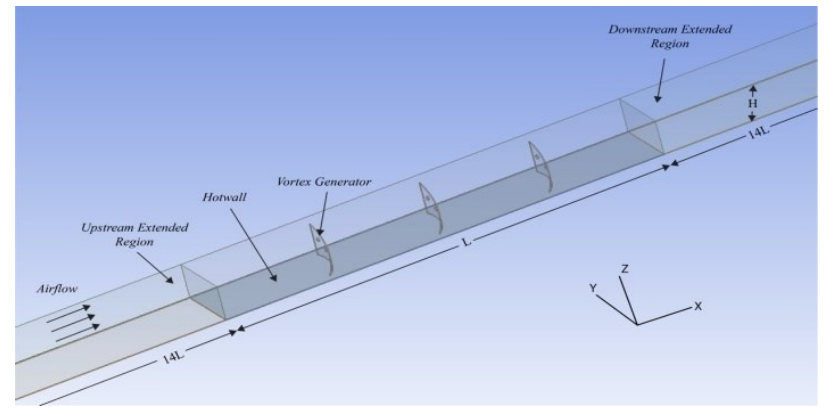

(b)

Figure 4. Computational domain along with its coordinate system: (a) Top view and (b) Three dimension

\section{Numerical solution}

The equation of conservation of mass, momentum, and energy is used as a governing equation in this work. The calculation was performed in a steady state. The fluid was assumed to be incompressible ideal gas. Based on the calculation of Reynolds numbers for velocity variations from 0.4 to $2.0 \mathrm{~m} / \mathrm{s}$, the fluid was modeled as a laminar flow at a velocity of $0.4 \mathrm{~m} / \mathrm{s}$ and turbulent flow at velocities greater than $0.4 \mathrm{~m} / \mathrm{s}$. Vortex generators (VGs) were assumed to be adiabatic. The standard $k-\omega$ turbulent model was used to model turbulent flow in the current study. Boundary conditions were needed to solve the governing equations used in this work. These boundary conditions in more detail can be seen in the previous paper [11].

The accuracy of the simulation results is determined by either the size or shape of the mesh. Mesh was distinguished between computational domains with extended inlet and outlet. The type of mesh used in the extended inlet region and the extended outlet region was hexahedral. The reason for this is that the extended inlet and outlet region have simple geometries. Meanwhile, the test section where VGs are installed used a tetrahedral mesh due to its complexity.

In this study, governing equations with boundary conditions were solved using computational fluid dynamics. The $k$ - $\omega$ model was chosen in this numerical simulation because this model is suitable for modeling free shear flow and flow separation in the viscous region [13]. Pressure-velocity coupling was solved by using a semi-implicit method for pressure-linked (SIMPLE) algorithm. The governing equation for momentum, energy, turbulent kinetic energy, specific dissipation rate was discretized by the second-order upwind scheme. This simulation must meet the convergence criteria set less than $10^{-5}, 10^{-6}$, and $10^{-8}$ for continuity, momentum, and energy equations, respectively. Under-relaxation factors for pressure, momentum, and energy were $0.3,0.7$, and 0.9 , respectively.

To obtain accurate simulation results, independent grid testing was carried out to ensure that the numerical simulation results are not affected by the number of grids. In this independent grid test, simulations were carried out on four different number of grid variations with the computational domain of three pairs of CDW VGs at a velocity of $0.4 \mathrm{~m} / \mathrm{s}$. In this numerical simulation, the number of grids from $1,200,000$ to $1,900,000$ was tested to obtain an independent grid. From the grid variations tested, the grid with the number of elements approaching 1,600,000 was 
the optimum number of grids compared to the other number of grids. Therefore, the number of grids approaching $1,600,000$ was chosen in this study.

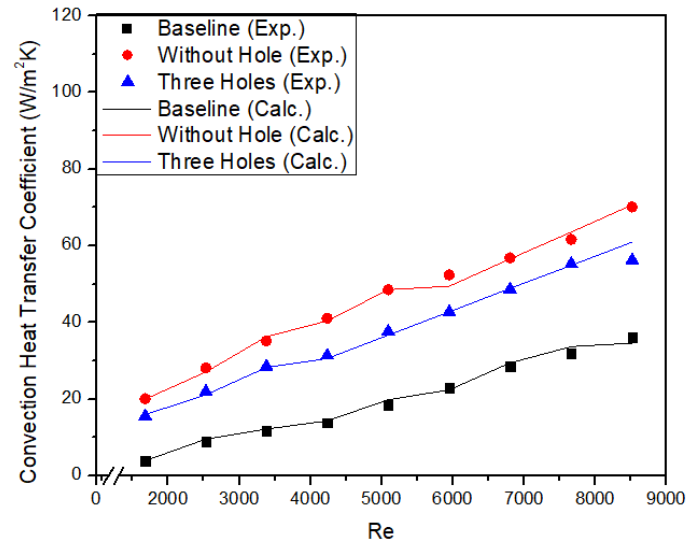

Figure 5. Comparison of convection heat transfer coefficient between numerical simulation and experiment results for three-pairs of DW VGs at variations of Reynolds numbers

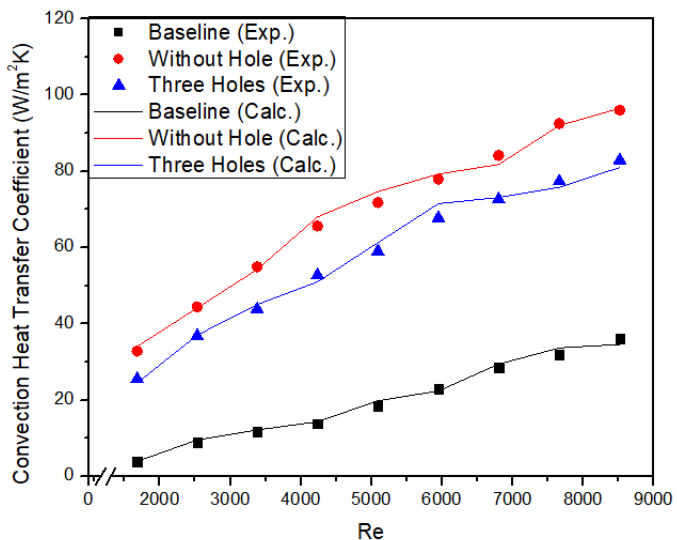

Figure 6. Comparison of convection heat transfer coefficient between numerical simulation and experiment results for three-pairs of CDW VGs at variations of Reynolds numbers

\section{RESULTS AND DISCUSSION}

\section{Effect of vortex generators on heat transfer}

The effect of VGs on heat transfer can be observed by evaluating the value of the convection heat transfer coefficient, which is determined based on the equations listed in Ref. [11]. Figures 5 and 6 show a comparison of the convection heat transfer coefficients for DW and CDW VGs cases resulting from the simulation and experiment. Both in the case of DW and CDW VGs, the convection heat transfer coefficient increases with increasing Reynolds number due to increased longitudinal vortex strength and fluid mixing [17]. The highest increase in convection heat transfer coefficient was found at $\mathrm{Re}=8600$ for all variations in the number of pairs for both the CDW and DW VGs cases as shown in Figures 5 and 6.

Overall, the convection heat transfer coefficient for the CDW VGs case is higher than that for the DW VGs case because the intensity of the longitudinal vortex produced by the CDW VGs is higher than the DW VGs caused by the pressure difference between VGs [18]. The increase in convection heat transfer coefficient at Reynolds number of 8600 for the case of perforated CDW and DW VGs are $134.29 \%$ and $76.19 \%$, respectively, compared to the baseline. The convection heat transfer coefficient increases with the addition of the number of VG pair due to interference with the boundary layer and an increase in fluid mixing $[19,20]$. Increasing the value of heat transfer coefficient for the case of perforated DW VGs at the $\mathrm{Re}=8600$ is $76.19 \%$ against the baseline. Meanwhile, the increase in the heat transfer coefficient for the perforated CDW VGs at the same Reynolds number is $134.29 \%$ compared to the baseline. Holes at VGs cause the convection heat transfer coefficient to decrease slightly, which is influenced by the intensity of the longitudinal vortex [21].

\section{Effect of vortex generators on pressure drop}

The comparison of the pressure drop between the simulation and experimental results for the DW and CDW VGs is shown in Figures 7 and 8. As can be seen in these figures, it is found a similar tendency between the results of experiments and simulations. From the experiment and simulation results, it can be observed that the pressure drop increases with increasing Reynolds numbers for all cases. The pressure drop in the CDW VGs case is greater than that of the DW VGs case because the frontal area for the CDW VGs is greater than the DW VGs [11]. The increase in 
pressure drop for perforated CDW VGs cases is 6.85 times to the baseline at $\mathrm{Re}=8600$. The decrease in pressure drop at $\mathrm{Re}=8600$ for the case of perforated DW and CDW VGs is $5.2 \%$ and $7 \%$ compared with no holes.

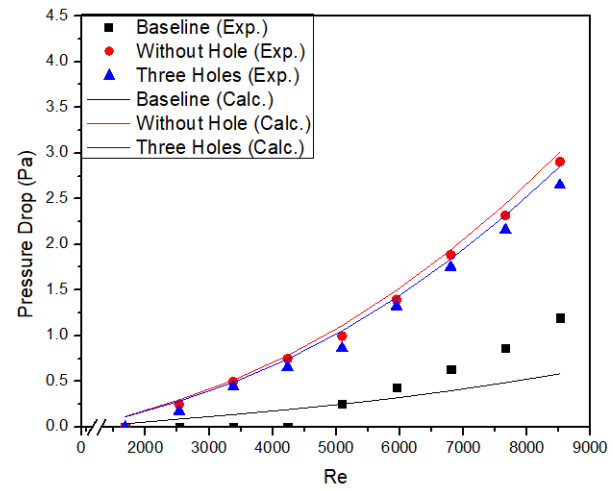

Figure 7. Comparison of pressure drop between numerical simulation and experiment results for different pairs of DW VGs at variations of Reynolds numbers

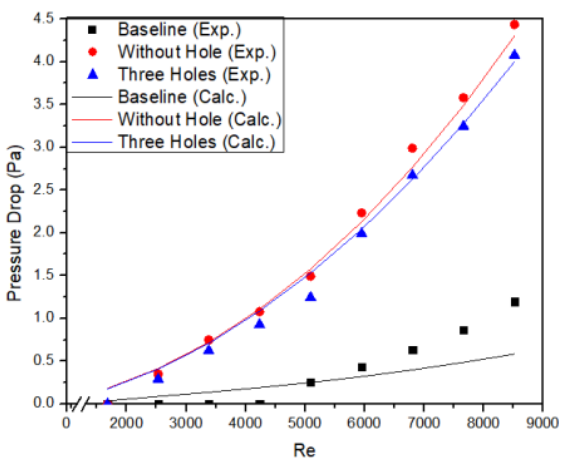

Figure 8. Comparison of pressure drop between numerical simulation and experiment results for different pairs of CDW VGs at variations of Reynolds numbers

\section{Field synergy analysis}

The field synergy principle is a method used to determine the improvement of convection heat transfer [18]. In this method, a decrease in the intersection angle between the velocity vector and the temperature gradient indicates an improvement in convection heat transfer called the field synergy angle ( $\beta$ ) [21]. Figures 9 and 10 show the local synergy angle field for DW and CDW VGs at Reynolds numbers of 1600 and 8600 . The decrease in the synergy angle in laminar case $(\operatorname{Re}=1600)$ tends to be higher than in turbulent case because velocity vectors in the stream-wise direction increases and the temperature gradient in stream-wise direction cannot develop properly [20]. For three pairs of perforated CDW VGs at $\mathrm{Re}=1600$, the lowest synergy angle observed at $\mathrm{x} / \mathrm{L}=0.28,0.52$, and 0.76 is $71.18^{\circ}$, $78.34^{\circ}$, and $82.83^{\circ}$, respectively. Meanwhile, in the case of DW VGs with the same configuration and Reynolds number, the minimum peak point is found at $\mathrm{x} / \mathrm{L}=0.32,0.56$, and 0.80 with the synergy angle of $77.83^{\circ}, 79.46^{\circ}$, and $77.76^{\circ}$, respectively. This indicates that the installation of CDW VGs results in a decrease in synergy angle greater than DW VGs because the strength of longitudinal vortex generated by the CDW VGs is higher than that of DW VGs.

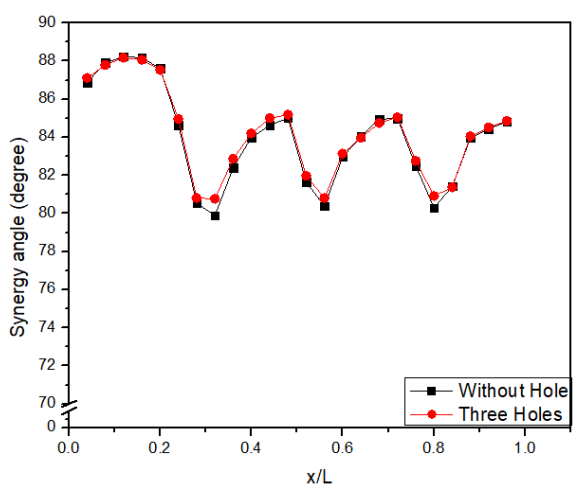

Figure 9. Local synergy angles for both with and without holes mounted by three pairs of DW VGs

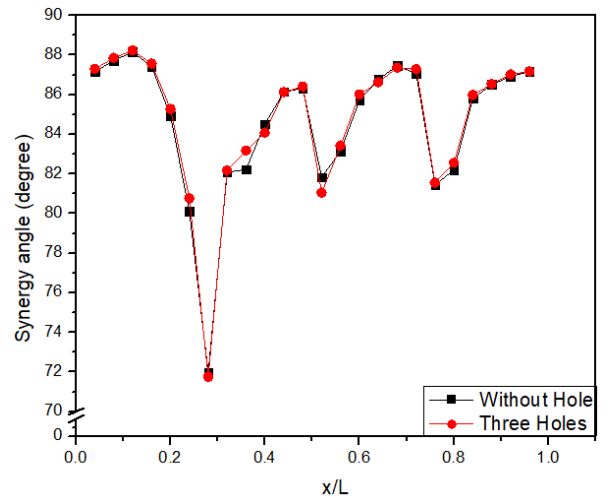

Figure 10. Local synergy angles for both with and without holes mounted by three pairs of CDW VGs 


\section{CONCLUSION}

In this study, numerical simulation of fluid flow through perforated CDW and DW VGs at 450 attack angle were conducted to investigate their effect on heat transfer and pressure drop. The conclusions that can be drawn from this study are as follows:

1. Giving holes in the vortex generator causes the convection heat transfer coefficient to decrease slightly.

2. Holes in the DW and CDW VGs caused the pressure drop to decrease.

3. Synergy angle for the case of perforated VGs provided slightly higher than that without hole.

\section{ACKNOWLEDGMENTS}

This work was supported by Department of Mechanical Engineering, Faculty of Engineering, Diponegoro University, Indonesia.

\section{REFERENCES}

1. P.B.Thakre, P.R Pachghare, "Performance Analysis on Compact Heat Exchanger", Materials Today: Proceedings 4 (2017) 8447-8453

2. Zuoqin Qian, Qiang Wang, Junlin Cheng, International Journal of Heat and Mass Transfer 124, 1198-1211 (2018).

3. M. Fiebig, A. Valencia, N.K. Mitra, Experimental Thermal and Fluid Science 7, 287-295 (1993).

4. Agung Tri Wijayanta, Tri Istanto, KeishiKariya, and Akio Miyara, Experimental Thermal and Fluid Science 87, 141-148 (2017).

5. L.H. Tang, W.X. Chu, N. Ahmed, and M. Zeng, Applied Thermal Engineering 104, 74-84 (2016).

6. Xiang Wu, Zhi-Min Lin, Song Liu, Mei Su, Liang-Chen Wang, and Liang-Bi Wanga, Applied Thermal Engineering 119, 560-572 (2017).

7. Hung-Yi Li, Wan-Rong Liao, Tian-Yang Li, and Yan-Zuo Chang, International Journal of Heat and Mass Transfer 112, 940-949 (2017).

8. Yonggang Lei, Fang Zheng, Chongfang Song, and Yongkang Lyu, International Journal of Heat and Mass Transfer 111, 299-311 (2017).

9. A. Esmaeilzadeh, N. Amanifard, and H.M. Deylami, Applied Thermal Engineering 125, 1414-1425 (2017)

10. Syaiful, Astrid Ayutasari, Maria F. Soetanto, Ahmad Indra Siswantara, and Myung-whan Bae, International Journal of Technology 7, 1276-1285 (2017).

11. Uddip Kashyap, Koushik Das, and Biplab Kumar Debnath, International Journal of Thermal Sciences 127, 6178 (2018).

12. C.D. Argyropoulos and N.C. Markatos, Applied Mathematical Modelling 39, 693-732 (2015).

13. KeWei Song, Toshio Tagawa, ZhongHao Chen, and Qiang Zhang, International Journal of Thermal Sciences 137, 215-228 (2019).

14. Shailesh Kumar Sarangi and Dipti Prasad Mishra, Applied Thermal Engineering 116, 528-540 (2017).

15. Zhaoqing Ke, Chung-Lung Chen, Kuojiang Li, Sheng Wang, and Chien-Hua Chen, International Journal of Heat and Mass Transfer 132, 871-885 (2019).

16. P.S.B. Zdanski, D. Pauli, and F.A.L. Dauner, International Communications in Heat and Mass Transfer 67, 8996 (2015).

17. Konstantin Volkov, Heat Transfer Models, Methods, and Applications (IntechOpen, London, 2018), pp. 219235

18. Zhimin Han, Zhiming Xu, and Jingtao Wang, International Journal of Heat and Mass Transfer 126, 993-1001 (2018).

19. Z.Y. Guo, W.Q. Tao, and R.K. Shah, International Journal of Heat and Mass Transfer 48, 1797-1807 (2005).

20. Wen-Quan Tao, Zeng-Yuan Guo, and Bu-Xuan Wang, International Journal of Heat and Mass Transfer 45, 3849-3856 (2002).

21. Gaofeng Lu and Guobing Zhou, International Journal of Thermal Sciences 109, 323-333 (2016). 